Portland State University

PDXScholar

Engineering and Technology Management

Faculty Publications and Presentations

8-1-2015

\title{
A Comprehensive Assessment of Cloud Computing for Smart Grid Applications:A Multi-Perspectives Framework
}

\author{
Nina Chaichi \\ Portland State University \\ Joao Lavoie \\ Portland State University \\ Soheil Zarrin \\ Portland State University \\ Rafaa Khalifa \\ Portland State University \\ Felix Sue \\ Portland State University
}

Follow this and additional works at: https://pdxscholar.library.pdx.edu/etm_fac

Part of the Operations Research, Systems Engineering and Industrial Engineering Commons Let us know how access to this document benefits you.

\section{Citation Details}

Chaichi, N., Lavoie, J., Zarrin, S., Khalifa, R., \& Sie, F. (2015, August). A comprehensive assessment of cloud computing for smart grid applications: A multi-perspectives framework. In Management of Engineering and Technology (PICMET), 2015 Portland International Conference on (pp. 2541-2547). IEEE.

This Article is brought to you for free and open access. It has been accepted for inclusion in Engineering and Technology Management Faculty Publications and Presentations by an authorized administrator of PDXScholar. Please contact us if we can make this document more accessible: pdxscholar@pdx.edu. 


\title{
A Comprehensive Assessment of Cloud Computing for Smart Grid Applications: A Multi-Perspectives Framework
}

\author{
Nina Chaichi, Joao Lavoie, Soheil Zarrin, Rafaa Khalifa, Felix Sie \\ Dept. of Engineering and Technology Management, Portland State University, Portland, OR - USA
}

\begin{abstract}
The IT system is one of the key infrastructures in order to add intelligent feature to power grids. Many papers anticipated a rocky road for IT system integration into power system and suggested the cloud computing adoption as a smart grid IT infrastructure to smooth the integration. Though cloud computing could overcome some of these integration challenges, it would bring some of its own. This study intends to give more insight to decision makers or utility companies to make a better decision whether to adopt cloud computing with regards to their needs or not. In the problem statement section is explained why the current approach to define advantages and disadvantages of cloud computing from selective point of views is not enough and might not be accurate, and a comprehensive assessment is required. The proposed multi-perspective framework takes all the criteria that would affect the assessment of cloud computing and put them into organizational, technical, economical, social and political categories. This framework would guide players in smart grid to better define benefits and challenges of cloud computing according to their needs.
\end{abstract}

\section{INTRODUCTION}

21st century demands reliable power networks. Environmental, economical, and political drivers would force electricity resources toward sustainable and cleaner ones, such as renewable energy, demand side resources and increased operational efficiency. Though these changes make it harder to maintain reliability, integration of Information Technology and Communications Technology into the power systems would raise awareness about real-time status of the system, and combining this awareness with suitable course of actions would result in smart and reliable grids. Therefore, smart grids consume big, real-time data and require powerful processing power to recognize the right course of actions. The IT system is the intelligent part of smart grids, so the path toward smart grids would go through pervasive adoption of IT systems. Though infusion of IT system is the beginning step, smart grids will happen through diffusion of IT systems. Smart grids IT system infusion and diffusion issues are discussed in [1]. Discussed infusion issues are "Not having clearly defined end state, The high cost of implementation, Non-conventional or large capital projects significant lead time, The incremental and evolving nature of applications[1]" and diffusion issues are " The many legacy business functions and system they touch, A rollout with minimum impact on existing operations, The required data interfaces with external and third party systems, The incremental and evolving nature of applications [1]".
Nowadays, Cloud computing trace could be detected everywhere. With regards to requirements and problems of implementing IT system for smart grids, many literature find on-demand, cost efficient and scalable cloud solution promising to accelerate this implementation. Though so many literature studied the advantages and disadvantages of cloud computing for smart grid applications [1][2][3], architectures [4][5], and security and privacy issues[6][7], there is no holistic view to aid decision making and interoperable design process. This paper tries to study the adoption of cloud computing for smart grid applications from different perspective to give broader insight to improve decision and design quality.

The rest of the paper organized as follow. Literature review on cloud-based IT system for smart grids has been done in section II. Section III states the problems with previous approach. Section IV explains methodology. A comprehensive multi perspectives framework to assess cloud computing is described in section V. Section VI-VIII respectively explain discussion, conclusion and future study.

\section{LITERATURE REVIEW}

\section{A. Analyzing cloud computing for smart grid}

There are several attempts to analyze capability, challenges and usability of cloud computing for the smart grid. Security and privacy issues in a Smart Grids software architecture operating on different Cloud environments are analyzed in [6], the advantages of cloud computing for India's smart grid are introduced in [8], the feasibility of utilizing cloud computing for smart grids is analyzed in [9], the technical and economical advantages of using CC for SG are analyzed in [10], cloud computing techniques for smart grid design are evaluated in [11], cloud computing as a service model for smart grids usage is discussed in [12], the current research problems in the areas of cloud-based energy management, information management, and security in smart grid are identified in [3], cloud computing opportunities and challenges for smart grid applications from technical, security and compatibility perspectives are described in [13]. Table 1. summarizes strength and weakness of cloud computing mentioned in literature. Some of the features are listed both as strength and weakness which indicates the need for more contextual studies. 
2015 Proceedings of PICMET '15: Management of the Technology Age

\begin{tabular}{|c|c|c|c|c|c|c|c|c|c|c|}
\hline Benefit & {$[1],[6],[3]$} & [13], [14] & $\begin{array}{l}1],[3], \\
{[6],[10],} \\
{[12],[13],} \\
{[14],[15],} \\
{[16],[17]}\end{array}$ & $\begin{array}{l}\text { [6], [11], } \\
{[18]}\end{array}$ & $\begin{array}{l}\text { [9], [12], } \\
{[13]}\end{array}$ & $\begin{array}{l}3],[7], \\
{[9],[14],} \\
{[18],[19],} \\
{[20],[21]}\end{array}$ & $\begin{array}{l}{[7],[18],} \\
{[20]}\end{array}$ & $\begin{array}{l}11],[3],[9], \\
{[10],[11],} \\
{[12],[13],} \\
{[15],[16],} \\
{[22],[23],} \\
{[24]}\end{array}$ & {$[3],[11],[17],[24]$} & \\
\hline Challenge & $\begin{array}{l}{[12],[13],} \\
{[14],[15],} \\
{[17],[19],} \\
{[20],[22],} \\
{[23],[24],} \\
{[25]}\end{array}$ & $\begin{array}{l}{[6],[14],} \\
{[15],[17],} \\
{[20],} \\
{[22],[24]}\end{array}$ & & & & & & & & [13] \\
\hline
\end{tabular}

\section{B. Cloud computing capability enhancement for smart grid}

Security is one of cloud computing features that looked differently in the smart grid area. Due to lack of IT system expertise in the power industry, in [26] the architecture of electric power information security is proposed based on cloud security as a service. Though security offered by cloud computing vendors [27] and their decency from different utilities' perspective are not the same, better security is required for pervasive use of cloud computing. The Following studies refer to some attempts to strengthen the cloud security. In [8], authors focused on distributed verification protocol to guarantee the data storage security in cloud computing for India's Smart Grid, [28] focused on the potential security risks in power cloud construction and related security protection technologies for power cloud, [18] proposed an architecture for data storage in the open source cloud platform for smart grid applications and test performance in Openstack cloud, [7] proposed searchable encryption scheme to secure sensitive clouding data of electric power systems, and [29] proposed trustworthy clouds, clouds with enhanced resistancy, privacy and tolerance against internal and external issues for smart grids usage. Besides security, performance of cloud computing and its readiness for smart grid use. [30] showed how to enhance basic cloud platform options with sophisticated technology to achieve the required levels of usability, fault tolerance, and parallelism.

\section{Cloud-based smart grids architecture}

The IT system is an essential infrastructure for smart grid, and the following research tried to provide architecture to build smart grid on cloud computing - on-demand IT system. [25] proposed architecture of intelligent cloud for electric power systems, [5] proposed a private cloud computing architecture to support smart grids, [9] proposed cloud-client architecture for smart grids based on agent-based technology, [4] proposed cloud based virtual smart grid architecture, [20] designed hybrid cloud computing platform for smart grids and suggested available products to build the platforms.

\section{Cloud-based smart grids applications}

Our literature review shows that most research emphasize on designing smart grid applications based on cloud computing or practical experience with implementing them on cloud. The efforts on modeling cloud-based smart grid applications are categorized into three categories: data and information analysis, monitoring and control and demand-side management.

Research on data and information modeling are as follows: [14] proposed cloud-based data management model for smart grids with preserving confidentiality and privacy of data, [31] proposed layered model to do resource scheduling and synergistic management by using Mobile-agent to build power systems cloud computing platform, [32] proposed a cloudbased service-oriented architecture to develop an energy management system, [23] proposed a cloud-based smart grid information management model, [33] proposed an architecture and design of cloud-based large-scale real-time data analysis system for smart grid, [22] proposed a cloud-based SG information system and a resource optimization framework.

Research on monitoring and control systems modeling are as follows: [34] proposed the design for cloud-based serviceoriented smart grid power monitoring and early warning services, [10] proposed $\mathrm{CC}$ architecture for renewable energy monitoring, [30] described cloud-based monitoring framework that can address reliability, timeliness and security issues, [35] proposed control model for microgrids with the hierarchical structure based on cloud computing architecture, [16] proposed cloud-based multi-agent system as a distributed control architecture for Smart Micro Grids.

Research on demand-side management system modeling are as follows: [36] presented requirements for a utility-side IT infrastructure to process incoming smart meter data streams and proposed cloud infrastructure to address the requirements, [36] cloud-based demand response, [21] approach to build interface between industrial consumer, smart grid and cloud computing, [38] proposed cloud-based knowledge system for end users to manage energy consumption, [39] introduced netbook advance metering infrastructure (Net-AMI), cloud based communication and optimization infrastructure to support a cognitive radio network of AMI meters, [40] proposed cloud-based platform to perform intelligent demandside management, [41] proposed cloud-based interface for two way real-time information exchange between electric vehicle supply equipment and utilities. 


\section{PROBLEM STATEMENT}

Some of the features that make cloud computing appealing for different businesses are introduced as: non-upfront investment, lowering operating cost, highly scalable, easy access, and reducing business risks and maintenance expenses [42] in cloud computing literature. However, with respect to table 1, the features emphasized as advantages of cloud computing in smart grid domain are processing power, storage capability, scalability, flexibility, cost efficiency, real-time response, and interconnectivity. But there is controversy on security and privacy, since some find them as advantages and other as disadvantages of cloud computing.

The rest of this section is organized to shed more light on these features and how different situations and decisions could force them out of the advantages zone and into the disadvantages zone and vice versa. It is important to realize the necessity of contextual analysis to understand the benefits and weaknesses of cloud computing from multi- perspectives.

With regards to security and privacy of cloud computing, expertise level of utilities with IT system and smart grids vulnerability are needed to be considered along. Smart grids are highly dependent on information transmission to monitor, control and coordinate power system through gathering data and sending correct signals. Different devices such as sensors, smart meters and so on would be implemented to do these information gathering and transmission are considered as vulnerable targets for cyber attacks [24], [43], [44]. Three common information attacks in smart grids are as follows:

1. Availability: make resources unavailable by hindering information transmission [44], [45]

2. Integrity: deliberately manipulating data to mislead utilities' decisions [44], [45], [46], [47]

3. Privacy: unauthorized acquisition of desired shared information [44], [45]

The important consideration about the security and privacy issues with utilizing cloud computing is whether it introduce new issues or exacerbate the issues that has already been detected in the smart grids. Cloud computing security concerns are the loss and leak of information [48]. These concerns with cloud computing security are raised with respect to shared and dynamic resources, reduced user's control on data storage, ambiguity in definition of security and privacy of services by cloud vendors [49] and lack of data security standards [48]. Though more in depth study is required, cloud computing utilization exacerbates privacy issues of smart grid.

Privacy also could be defined as misuse of authorized information rather than unauthorized acquisition of information. More different types of information gathered and shared in power systems is better for smart grid purposes, but it comes with the cost of jeopardizing agents' privacy. Gathering and sharing decent information with preserving privacy is not an easy task in smart grid [24]. For instance, shared data by customers could be potential risk to their privacy since it could reveal their habits, behavior, activities, preferences and beliefs [50]. Using cloud computing services could potentially expose users to this type of privacy risk.

One of the factors that affect the level of security and privacy issues is the deployment model of cloud. The followings explain three common deployment models for cloud:

1. Public Cloud: all the IT infrastructure managing decisions such as geographical location of data, service architecture and etc. are being taken by cloud vendor.

2. Private Cloud: organization controls and manages all their own resources in cloud system.

3. Hybrid Cloud: combination of the private and public clouds.

In [13] described how the deployment model would affect security and other advantages, private cloud loses all the cloud advantages but it is highly secure and the difference between public and hybrid cloud is a trade-off between security and compatibility vs. complexity and cost efficiency, though these arguments are subject to change under different situations from this study's point of view.

Another factor that would affect the advantages and disadvantages of cloud computing for smart grid is cloud service model, different types of cloud service model described as follows:

1. Iaas (Infrastructure as a service): Hire IT system infrastructure (storage, processor and etc) for the period of time that best suits the customer needs.

2. Paas (Platform as a service): Utilize cloud tools to develop, deploy or test the applications without any control over infrastructure.

3. Saas (Software as a service): ready-to-go applications from any device connected to the internet, without having to install and manage them.

For instance, using Saas model might improve the security levels only if data would be stored on private storage. Along with the service model, the chosen network to transfer data would have an effect on analysis. In some of the literature, the interconnectivity of cloud computing is mentioned as an advantage for smart grid where public internet is chosen as an in-use network. Using public network would expose smart grid to all the internet threats such as malicious software, denial of service and etc, since cloud vendor has better knowledge to deal with these threats, [26] proposed a power information architecture based on cloud security.

Though interconnectivity is considered as an advantage of cloud, interconnectivity solely without satisfying interoperability would not meet smart grid requirements. Lack of globally accepted standards makes interoperability of cloud computing a big issue [51].

From a performance perspective, the quality of cloud services required by smart grid is strict. Cloud computing requires to provide real-time responsiveness, guaranteed consistency, data security, fault-tolerance at the same time 
[52] to be usable for smart grid application. Though many studies described the advantages of cloud computing, very few of them mentioned the usability of cloud for smart grid.

The whole point of this section is to show how determining advantages and disadvantages of cloud computing from selective point of views might not be completely accurate. In the next section, a multi-perspective framework will be introduced to guide utilities with different responsibilities and characteristics to comprehensively assess the cloud computing for their needs.

\section{METHODOLOGY}

Always several elements or criteria are considered to assess any technology - for some models preaching this approach see [53], advantage and disadvantages of cloud computing are listed in literature review section is an example of that. Harold A. Listone argued in [54] that how to consider criteria is equally important as what to consider to assess technology. He set the foundation for evaluating technologies from multiple perspectives consists of technical (T), organizational $(\mathrm{O})$ and personal $(\mathrm{P})$ perspectives. Technical perspective overviews technology and its environment, organizational perspective represents the effects that technology has on organization and vice versa, and personal perspective puts into consideration all of impacts of technology on individuals such as self-interest and etc. In TOP model, after determining - what needs to be consideredcriteria or elements, they are mapped into three categories or perspectives to illuminate how to consider them. Each elements would be perceived from the perspective that it is listed in. The perspectives could be extended beyond TOP perspectives, in [55] photovoltaic technology is assessed from social, technological, economic, environmental, and political (STEEP) perspectives. In next section, multiple perspectives framework is introduced to evaluate cloud computing for smart grid applications.

\section{A COMPREHENSIVE MULTIPLE PERSPECTIVES FRAMEWORK}

Harold A. Linstone stated in [56] and it has been shown in literature review section, different actors have different perspectives when facing a given situation. It is proved that there are advantages in viewing the same problem from different perspective [56]. Problem statement section explains the problem associated with assessing cloud computing technology based on limited elements and perspective. Table 2. illustrates comprehensive framework to assess cloud computing. In this study, fundamental perspectives are introduced by Harold A. Linstone, expanded as: organizational, technical, social, economical, and political perspectives. These perspectives are defined as follows.

1. Organizational perspective: the criteria are needed to be considered from originations' perspective which are active in smart grid domain to define advantages and disadvantages of cloud computing.

2. Technical perspective: all the technical features required for usability of cloud computing for smart grid application.

3. Social perspective: the criteria are needed to be considered from society's perspective - In this context, end-users to define advantages and disadvantages of cloud computing. This perspective has not considered in previous research. Since, there are some similarities between adoption of personal health record (PHR) system and of end-users' IT system, this perspective and its elements are build based on the discussion in PHR adoption literature [57].

4. Economical perspective: the criteria needs to be considered when measuring the economical value of cloud computing.

5. Political perspective: Political movements that could affect advantages and disadvantages of cloud computing.

Table 2. illustrates all 5 perspectives and all the criteria associated with each and every perspectives. The criteria are gathered from different contexts which authors find related to the topic, the contexts such as pervious similar research discussed in literature review section, smart grid research mentioned in introduction and problem statement sections, and related technology evaluation like PHR. Followings are description of each criteria mentioned in table 2.

\section{A. Organizational Perspective}

- Security: Any activity to hinder data transmission, manipulate data, or access to utilities information without authorization.

TABLE 2 - CRITERIA FOR EACH PERSPECTIVES

\begin{tabular}{|c|c|c|c|c|}
\hline Organizational & Technical & Economical & Social & Political \\
\hline Security & Real-time responsiveness & Scalability & Incentives & Policies \\
\hline Privacy & Consistency & Flexibility & Privacy & $\begin{array}{c}\text { Government R\&D } \\
\text { Framework }\end{array}$ \\
\hline Subject matter knowledge & Fault-tolerant & Cloud service model & Security & $\begin{array}{c}\text { Code / Standards - } \\
\text { Compliance }\end{array}$ \\
\hline Culture & $\begin{array}{c}\text { Performance latency / } \\
\text { availability }\end{array}$ & $\begin{array}{c}\text { Cloud deployment model } \\
\text { Strategy }\end{array}$ & $\begin{array}{c}\text { Complementary } \\
\text { technologies availability }\end{array}$ & \\
\hline & Technology maturity & Security reinforcement & & \\
\hline & Technology roadmap & & Required training level & \\
\hline
\end{tabular}




\section{Proceedings of PICMET '15: Management of the Technology Age}

- Privacy: misuse the shared data for any reason rather than it supposed to used for. For instance, gaining business advantages.

- Subject matter knowledge: the level of organization knowledge to deal with IT system such as implementing, maintaining and etc. of IT system.

- Culture: organizations' preference to have more control over all the process or reducing business and maintenance risk by involving third parties.

- Strategy: approach in implementing the IT system and decisions towards operating and maintaining the system.

B. Technical Perspective

- Real-time responsiveness: ability of the system to respond in less than a specific time.

- Consistency: stability and accuracy of services provided by cloud computing.

- Fault-tolerant: resiliency of cloud computing against disaster such as adequacy of back of system and etc.

- Performance latency / Availability: the average amount of time that cloud services are not available.

- Interoperability: the ability of any cloud system to communicate, exchange data with other cloud and IT system or use data.

- Technology roadmap: plan that matches with short-term and long-term development goals of cloud computing. In other words, cloud computing vendors' strategies to improve status quo of technology are included in this criteria. [58] outlines the key forces that could shape the future of technology.

- Technology maturity: Cloud computing technology readiness level for operation in different environment. Top 10 obstacles and opportunities of cloud computing are listed in [59], moreover [60] stated that cloud computing technologies are still not mature and they are evolving and progressing.

\section{Economical Perspective}

- Scalability: Ability of system to expand for future development.

- Flexibility: Ability to fit required resources dynamically. It is important for pay per use cloud.

- Cloud service model: It has three forms; infrastructure as a service (Iaas), platform as a service (Paas), software as a service.

- Cloud deployment model: deployment model is related to the ownership of the system, there are different deployment models such as public, private, hybrid cloud computing and etc.

- Network deployment model: network is used to transmission data it cloud be either public internet or any dedicated network.

- Security reinforcement: New or existing technologies or methods are necessary to be added to boost the current status of cloud - different from one vendor to anotherto meet the security level required by the smart grid.

\section{Social Perspective}

- Incentives: end-user motivation to adopt cloud computing services.

- Privacy: misuse the shared data for any reason rather than it is supposed to be used for.

- Security: unauthorized interference in normal operation of end users' appliances and devices.

- Complementary technologies availability: availability of required technology to enable end-users to connect and use cloud services.

- Required training level: training required to enable endusers to connect and use cloud services.

\section{E. Political Perspective}

- Policies: government policies' that could strengthen or weaken the benefit of cloud computing for smart grid.

- Government R\&D framework: governmental support in form of grants and etc. to increase the cloud computing technology readiness for smart grid application, for instance the provided grant to develop Gridcloud [52].

- Code / standards - compliance: code and standards that affect merit and demerit of cloud computing. For instance, compliance with NERC CIP standards that insure the reliability of bulk power systems would be a challenge to adopt cloud computing. [61] analyze the problem with policy violation such as NERC CIP when system managed by two organizations (cloud users and providers).

\section{CONCLUSION}

The literature review section of this paper shows the efforts to assess cloud computing for smart grid applications, strengthen the security and proposes an architecture of smart grid and its applications based on cloud. Literature review, specially table 1 reveals the selective look into the problem utilize cloud computing for smart grid application — from different perspectives. In addition, the problem statement part described how adding other perspectives could change the result, since there is a trade-off between some criteria.

In order to fill the gap sensed in the literature, this paper proposed a multi-perspectives framework to help comprehensive assessment of cloud computing and better design for cloud-based smart grid. Smart grid has various agents with different responsibilities and requirements. Also, these agents need to interact with each other, which is a fundamental need of smart grid. The proposed framework gathered all the perspectives and mapped them into categories to enable different agents to assess cloud services and design cloud-based applications based on not only their own needs but also the interactions that are required in the smart grid. 


\section{FUTURE RESEARCH}

The proposed framework is based on literature, framework could be refined further based on the opinion of power system IT experts captured through survey or interview. Another improvement that could be done is to compare criteria and perspectives against each other to understand the importance of each of them. This study has not attempted to touch upon this area, since this comparison could be different from one case to another and from one type of utilities (Generation company, Transmission company, and etc.) or players (end users, market, and etc.) to others. Therefore, it needs to be addressed in a separate study. Last but not least, this study has not determined the relationship between criteria and the negative and positive effects, they might have on each other, since it might be different in each case and require an in depth study.

\section{REFERENCES}

[1] A. Ipakchi and F. Albuyeh, "Grid of the future," Power Energy Mag. IEEE, vol. 7, no. 2, pp. 52-62, 2009.

[2] R. C. Green, L. Wang, and M. Alam, "Applications and trends of high performance computing for electric power systems: Focusing on smart grid," IEEE Trans. Smart Grid, vol. 4, no. 2, pp. 922-931, 2013.

[3] S. Bera, S. Misra, and J. J. Rodrigues, "Cloud computing applications for smart grid: a survey," 2014.

[4] Y. Xin, I. Baldine, J. Chase, T. Beyene, B. Parkhurst, and A. Chakrabortty, "Virtual smart grid architecture and control framework," in Smart Grid Communications (SmartGridComm), 2011 IEEE International Conference on, 2011, pp. 1-6.

[5] L. Zheng, Y. Hu, and C. Yang, "Design and research on private cloud computing architecture to support smart grid," in Intelligent HumanMachine Systems and Cybernetics (IHMSC), 2011 International Conference on, 2011, vol. 2, pp. 159-161.

[6] Y. Simmhan, A. G. Kumbhare, B. Cao, and V. Prasanna, "An analysis of security and privacy issues in smart grid software architectures on clouds," in Cloud Computing (CLOUD), 2011 IEEE International Conference on, 2011, pp. 582-589.

[7] Y. Jiang, X. Guo, C. Li, H. Wen, C. Lei, and Z. Rui, "An efficient and secure search database scheme for cloud computing in smart grid," in Communications and Network Security (CNS), 2013 IEEE Conference on, 2013, pp. 413-414.

[8] B. A. Ugale, P. Soni, T. Pema, and A. Patil, "Role of cloud computing for smart grid of india and its cyber security," in Engineering (NUiCONE), 2011 Nirma University International Conference on, 2011, pp. 1-5.

[9] X. Jin, Z. He, and Z. Liu, "Multi-agent-based cloud architecture of smart grid," Energy Procedia, vol. 12, pp. 60-66, 2011.

[10] B. Bitzer and E. S. Gebretsadik, "Cloud computing framework for smart grid applications," in Power Engineering Conference (UPEC), 2013 48th International Universities', 2013, pp. 1-5.

[11] K. Maheshwari, K. Birman, J. Wozniak, and D. V. Zandt, "Evaluating cloud computing techniques for smart power grid design using parallel scripting," in Cluster, Cloud and Grid Computing (CCGrid), 2013 13th IEEE/ACM International Symposium on, 2013, pp. 319-326.

[12] D. S. Markovic, D. Zivkovic, I. Branovic, R. Popovic, and D. Cvetkovic, "Smart power grid and cloud computing," Renew. Sustain. Energy Rev., vol. 24, pp. 566-577, 2013.

[13] M. Yigit, V. C. Gungor, and S. Baktir, "Cloud Computing for Smart Grid applications," Comput. Netw., vol. 70, pp. 312-329, 2014.

[14] S. Rusitschka, K. Eger, and C. Gerdes, "Smart grid data cloud: A model for utilizing cloud computing in the smart grid domain," in Smart Grid Communications (SmartGridComm), 2010 First IEEE International Conference on, 2010, pp. 483-488.
[15] K. P. Birman, D. A. Freedman, Q. Huang, and P. Dowell, "Overcoming cap with consistent soft-state replication," Computer, no. 2, pp. 50-58, 2011.

[16] S. Bertagna De Marchi, F. Ponci, and A. Monti, "Design of a MAS as Cloud Computing Service to control Smart Micro Grid," in Innovative Smart Grid Technologies Europe (ISGT EUROPE), 2013 4th IEEE/PES, 2013, pp. 1-5.

[17] C. Sivapragash, S. R. Thilaga, and S. S. Kumar, "Advanced cloud computing in smart power grid," in Sustainable Energy and Intelligent Systems (SEISCON 2012), IET Chennai 3rd International on, 2012, pp. $1-6$.

[18] T. Rajeev and S. Ashok, "A cloud computing approach for power management of microgrids," in Innovative Smart Grid Technologies India (ISGT India), 2011 IEEE PES, 2011, pp. 49-52.

[19] J. Baek, Q. H. Vu, A. Jones, S. Al Mulla, and C. Y. Yeun, "Smartframe: A flexible, scalable, and secure information management framework for smart grids," in Internet Technology And Secured Transactions, 2012 International Conference for, 2012, pp. 668-673.

[20] F. Luo, Z. Y. Dong, Y. Chen, Y. Xu, K. Meng, and K. P. Wong, "Hybrid cloud computing platform: the next generation it backbone for smart grid," in Power and Energy Society General Meeting, 2012 IEEE, 2012, pp. 1-7.

[21] M. Geberslassie and A. Chemyaev, "The Basic Approaches of creating an interface between Industrial Enterprise, Smart Grid and Cloud Computing," in Universities' Power Engineering Conference (UPEC), Proceedings of 2011 46th International, 2011, pp. 1-5.

[22] X. Fang, D. Yang, and G. Xue, "Evolving smart grid information management cloudward: A cloud optimization perspective," Smart Grid IEEE Trans. On, vol. 4, no. 1, pp. 111-119, 2013.

[23] X. Fang, S. Misra, G. Xue, and D. Yang, "Managing smart grid information in the cloud: opportunities, model, and applications," Netw. IEEE, vol. 26, no. 4, pp. 32-38, 2012.

[24] X. Fang, S. Misra, G. Xue, and D. Yang, "Smart grid-The new and improved power grid: A survey," Commun. Surv. Tutor. IEEE, vol. 14, no. 4, pp. 944-980, 2012.

[25] L. Zheng, S. Chen, Y. Hu, and J. He, "Applications of cloud computing in the smart grid," in Artificial Intelligence, Management Science and Electronic Commerce (AIMSEC), 2011 2nd International Conference on, 2011, pp. 203-206.

[26] W. Yanliang, D. Song, L. Wei-min, Z. Tao, and Y. Yong, "Research of electric power information security protection on cloud security," in 2010 International Conference on Power System Technology (POWERCON), 2010, pp. 1-6.

[27] B. P. Rimal, E. Choi, and I. Lumb, "A taxonomy and survey of cloud computing systems," in INC, IMS and IDC, 2009. NCM'09. Fifth International Joint Conference on, 2009, pp. 44-51.

[28] Y. Yang, L. Wu, and W. Hu, "Security architecture and key technologies for power cloud computing," in 2011 International Conference on Transportation, Mechanical, and Electrical Engineering (TMEE), 2011, pp. 1717-1720.

[29] C. Sivapragash, S. R. Thilaga, and S. S. Kumar, "Advanced cloud computing in smart power grid," in Sustainable Energy and Intelligent Systems (SEISCON 2012), IET Chennai 3rd International on, 2012, pp. $1-6$.

[30] K. Maheshwari, M. Lim, L. Wang, K. Birman, and R. van Renesse, "Toward a reliable, secure and fault tolerant smart grid state estimation in the cloud," in Innovative Smart Grid Technologies (ISGT), 2013 IEEE PES, 2013, pp. 1-6.

[31] L. Tang, J. Li, and R. Wu, "Synergistic model of power system cloud computing based on Mobile-agent," in 2012 3rd IEEE International Conference on Network Infrastructure and Digital Content (IC-NIDC), 2012, pp. 222-226.

[32] C.-T. Yang, W.-S. Chen, K.-L. Huang, J.-C. Liu, W.-H. Hsu, and C.-H. Hsu, "Implementation of smart power management and service system on cloud computing," in Ubiquitous Intelligence \& Computing and 9th International Conference on Autonomic \& Trusted Computing (UIC/ATC), 2012 9th International Conference on, 2012, pp. 924-929.

[33] J. Yin, I. Gorton, and S. Poorva, "Toward real time data analysis for smart grids," in High Performance Computing, Networking, Storage and Analysis (SCC), 2012 SC Companion:, 2012, pp. 827-832. 
[34] L. Ji, W. Lifang, and Y. Li, "Cloud Service based intelligent power monitoring and early-warning system," in Innovative Smart Grid Technologies-Asia (ISGT Asia), 2012 IEEE, 2012, pp. 1-4.

[35] T. Rajeev and S. Ashok, "Operational Flexibility in Smart Grid through Cloud Computing," in Cloud and Services Computing (ISCOS), 2012 International Symposium on, 2012, pp. 21-24.

[36] B. Lohrmann and O. Kao, "Processing smart meter data streams in the cloud," in 2011 2nd IEEE PES International Conference and Exhibition on Innovative Smart Grid Technologies (ISGT Europe), 2011, pp. 1-8.

[37] H. Kim, Y.-J. Kim, K. Yang, and M. Thottan, "Cloud-based demand response for smart grid: Architecture and distributed algorithms," in Smart Grid Communications (SmartGridComm), 2011 IEEE International Conference on, 2011, pp. 398-403.

[38] V. Nikolopoulos, G. Mpardis, I. Giannoukos, I. Lykourentzou, and V. Loumos, "Web-based decision-support system methodology for smart provision of adaptive digital energy services over cloud technologies," IET Softw., vol. 5, no. 5, pp. 454-465, 2011.

[39] K. Nagothu, B. Kelley, M. Jamshidi, and A. Rajaee, "Persistent NetAMI for Microgrid Infrastructure Using Cognitive Radio on Cloud Data Centers," IEEE Syst. J., vol. 6, no. 1, pp. 4-15, Mar. 2012.

[40] Y. Simmhan, S. Aman, A. Kumbhare, R. Liu, S. Stevens, Q. Zhou, and V. Prasanna, "Cloud-Based Software Platform for Big Data Analytics in Smart Grids," Comput. Sci. Eng., vol. 15, no. 4, pp. 38-47, Jul. 2013.

[41] S. M. Hasan, A. Reid, M. Nielsen, and K. Dodrill, "Cloud connected smart grid enabled EVSE," in Connected Vehicles and Expo (ICCVE), 2013 International Conference on, 2013, pp. 824-825.

[42] Q. Zhang, L. Cheng, and R. Boutaba, "Cloud computing: state-of-theart and research challenges," J. Internet Serv. Appl., vol. 1, no. 1, pp. 7$18,2010$.

[43] S. W. Smith, "Security and privacy challenges in the smart grid," 2009.

[44] F. M. Cleveland, "Cyber security issues for Advanced Metering Infrasttructure (AMI)," in Power and Energy Society General MeetingConversion and Delivery of Electrical Energy in the 21st Century, 2008 IEEE, 2008, pp. 1-5.

[45] Z. Lu, X. Lu, W. Wang, and C. Wang, "Review and evaluation of security threats on the communication networks in the smart grid," in MILITARY COMMUNICATIONS CONFERENCE, 2010-MILCOM 2010, 2010, pp. 1830-1835.

[46] Y. Liu, P. Ning, and M. K. Reiter, "False data injection attacks against state estimation in electric power grids," ACM Trans. Inf. Syst. Secur. TISSEC, vol. 14, no. 1, p. 13, 2011.

[47] Y. Yuan, Z. Li, and K. Ren, "Modeling load redistribution attacks in power systems," Smart Grid IEEE Trans. On, vol. 2, no. 2, pp. 382390, 2011.
[48] F. Hu, M. Qiu, J. Li, T. Grant, D. Taylor, S. McCaleb, L. Butler, and R. Hamner, "A review on cloud computing: Design challenges in architecture and security," CIT J. Comput. Inf. Technol., vol. 19, no. 1, pp. 25-55, 2011.

[49] C. N. Höfer and G. Karagiannis, "Cloud computing services: taxonomy and comparison," J. Internet Serv. Appl., vol. 2, no. 2, pp. 81-94, 2011.

[50] H. S. Cho, T. Yamazaki, and M. Hahn, "AERO: extraction of user's activities from electric power consumption data," Consum. Electron. IEEE Trans. On, vol. 56, no. 3, pp. 2011-2018, 2010.

[51] M.-E. Bégin, B. Jones, J. Casey, E. Laure, F. Grey, C. Loomis, and R. Kubli, "An egee comparative study: Grids and clouds-evolution or revolution," EGEE III Proj. Rep., vol. 30, 2008.

[52] D. Bakken, Smart Grids: Clouds, Communications, Open Source, and Automation. CRC Press, 2014.

[53] Y. Alizadeh, "Firm-level technological capability assessment; a literature review," in Technology Management Conference (ITMC), 2012 IEEE International, 2012, pp. 398-404.

[54] H. A. Linstone, "The multiple perspective concept: With applications to technology assessment and other decision areas," Technol. Forecast. Soc. Change, vol. 20, no. 4, pp. 275-325, 1981.

[55] N. Sheikh, T. Daim, and D. F. Kocaoglu, "Use of multiple perspectives and decision modeling for PV technology assessment," in Technology Management in the Energy Smart World (PICMET), 2011 Proceedings of PICMET'11:, 2011, pp. 1-21.

[56] H. A. Linstone, "Multiple perspectives redux," Technol. Forecast. Soc. Change, vol. 77, no. 4, pp. 696-698, 2010.

[57] J. S. Ash and D. W. Bates, "Factors and forces affecting EHR system adoption: report of a 2004 ACMI discussion," J. Am. Med. Inform. Assoc., vol. 12, no. 1, pp. 8-12, 2005.

[58] S. Marston, Z. Li, S. Bandyopadhyay, J. Zhang, and A. Ghalsasi, "Cloud computing-The business perspective," Decis. Support Syst., vol. 51, no. 1, pp. 176-189, 2011.

[59] M. Armbrust, A. Fox, R. Griffith, A. D. Joseph, R. Katz, A. Konwinski, G. Lee, D. Patterson, A. Rabkin, I. Stoica, and others, "A view of cloud computing," Commun. ACM, vol. 53 , no. 4 , pp. 50-58, 2010.

[60] L. Wang, G. Von Laszewski, A. Younge, X. He, M. Kunze, J. Tao, and C. Fu, "Cloud computing: a perspective study," New Gener. Comput., vol. 28 , no. 2, pp. 137-146, 2010.

[61] M. Montanari, L. T. Cook, and R. H. Campbell, "Multi-organization policy-based monitoring," in Policies for Distributed Systems and Networks (POLICY), 2012 IEEE International Symposium on, 2012, pp. $70-77$. 